\title{
O livro escolar como fonte de pesquisa em História da Educação
}

\author{
Rosa Lydia Teixeira Corrêa*
}

\begin{abstract}
RESUMO: Este artigo trata sobre o livro didático como fonte de pesquisa em História da Educação. Compreende-o como possuidor de valores que se desejou fossem transmitidos num dado momento histórico, ao mesmo tempo em que é portador de um projeto de nação a ser construído por meio da educação escolar. Entende que esse tipo de material faz parte do universo da cultura escolar residindo aí a importância da sua utilização para a compreensão das práticas escolares no interior das instituições educativas ao longo da história da educação. Tece considerações sobre sua produção e sua comercialização como elementos a considerar na sua organização.
\end{abstract}

Palavras-chave: Educação, história, práticas, escola, livro escolar

Importância do livro escolar como fonte de pesquisa em História da Educação

A utilização do livro escolar como fonte de pesquisa em história da educação é um assunto que merece ser retomado. Testemunhos de conteúdos de naturezas diversas no que tange a valores morais, éticos, sociais,

* Professora da Pontifícia Universidade Católica de Campinas.

E-mail: rosa_lydia@bol.com.br 
cívicos e patrióticos, os livros escolares que serviram ${ }^{2}$ de guia para professores e alunos ainda têm muito a ser desvendado. Desvendá-los requer que se tomem em consideração dois aspectos: primeiro, tratar-se de um tipo de material de significativa contribuição para a história do pensamento e das práticas educativas ao lado de outras fontes escritas, orais e iconográficas e, segundo, ser portador de conteúdos reveladores de representações e valores predominantes num certo período de uma sociedade que, simultaneamente à historiografia da educação e da teoria da história, permitem rediscutir intenções e projetos de construção e de formação social. Por isso, segundo Fonseca (1999),

o livro didático e a educação formal não estão deslocados do contexto político e cultural e das relações de dominação, sendo, muitas vezes, instrumentos utilizados na legitimação de sistemas de poder, além de representativos de universos culturais específicos. (...) Atuam, na verdade, como mediadores entre concepções e práticas políticas e culturais, tornando-se parte importante da engrenagem de manutenção de determinadas visões de mundo. (p. 204)

Para Lajolo e Zilberman (1999), entretanto,

apesar de ilustre, o livro didático é o primo pobre da literatura, texto para ler e botar fora, descartável porque anacrônico: ou ele fica superado dados os progressos da ciência a que se refere ou o estudante o abandona, por avançar em sua educação. Sua história é das mais esquecidas e minimizadas, talvez porque os livros didáticos não são conservados, suplantado seu "prazo de validade"."

Sem dúvida, alguns fatores determinam o anonimato do livro didático. O primeiro deles refere-se à sua natureza, que determina em certo sentido o seu destino final. Livro feito para ser usado em certa série ou grau de ensino, vai sendo descartado na medida em que cumpre sua finalidade escolar. O segundo relaciona-se à especificidade da leitura, que é profundamente marcada por sua natureza, e o terceiro deve-se a um tipo de mentalidade dominante no Brasil, particularmente no que se refere ao tratamento que é dado à memória de modo geral e à educação em particular. Nesse 
sentido não vamos muito longe. Pouquíssimos são os espaços dedicados à preservação da memória nacional ou regional da educação. Daí a dificuldade que temos de acesso a fontes nessa área. Na verdade, a pesquisa histórica em educação requer que realizemos um verdadeiro trabalho de "garimpagem" sobre fontes na área educacional.

Os livros escolares, de modo geral, configuram um objeto em circulação - como bem frisa Chartier (1990) - e, por essa razão, são veículos de circulação de idéias que traduzem valores, como já dissemos, e comportamentos que se desejou fossem ensinados. Some-se a isso o fato de que a relação entre livro escolar e escolarização permitem pensar na possibilidade de uma aproximação maior do ponto de vista histórico acerca da circulação de idéias sobre o que a escola deveria transmitir/ensinar e, ao mesmo tempo, saber qual concepção educativa estaria permeando a proposta de formação dos sujeitos escolares. Nesse sentido, então, esse tipo de fonte pode servir como um indicador de projeto de formação social desencadeado pela escola. Isso é permitido por meio das interrogações que podem ser feitas, quer em termos do conteúdo, quer de discurso, sem deixar de levar em consideração aspectos referentes a temporalidade e espaço. O que, por sua vez, possibilita indagar sobre a que e a quem serviu como um dos instrumentos da prática institucional escolar. Nesse aspecto em particular, vincula-se à história das instituições escolares e, amplamente, à das políticas educacionais.

Do ponto de vista das instituições escolares, sua contribuição está em, concomitantemente a outras fontes, possibilitar entender a instituição escolar por dentro, já que esse tipo de material é portador de parte dos conteúdos do currículo escolar naquilo que diz respeito ao conhecimento. Aliás, dependendo do período histórico no qual for tomado como fonte, esse tipo de material pode ser considerado como o portador supremo do currículo escolar no que tange aos conhecimentos que eram transmitidos nas diferentes áreas, quando se constituiu em única referência tanto para professores quanto para alunos.

As fontes historiográficas da educação, aí incluídos os livros, possuem "marcas transitórias de comportamento modelado, mostram-se estranhas, elípticas, incoerentes, suspeitas, tendenciosas, contaminadas, vivas" (Nunes 1992, p.158).

A utilização do livro escolar, na perspectiva aqui defendida, contribui para avançar na direção da pesquisa sobre a instituição escolar, no que diz 
respeito também à circulação e ao uso dos materiais de ensino em seu interior e estabelecer relações entre estes e as compreensões epistemológicas sobre a educação, a aprendizagem escolar, a didática e metodologia de ensino, no sentido de entendê-las através das práticas escolares, meios de seus desdobramentos concretos nessa instituição. Em última instância,

o livro didático interessa igualmente a uma história da leitura porque ele, talvez mais ostensivamente que outras formas escritas, forma o leitor. Pode não ser tão sedutor quanto as publicações destinadas à infância (livros de histórias em quadrinhos), mas sua influência é inevitável, sendo encontrado em todas as etapas da escolarização de um indivíduo: é cartilha quando alfabetização; seleta, quando da aprendizagem da tradição literária; manual quando do conhecimento das ciências ou da profissionalização adulta, na universidade. (Lajolo e Zilberman op. cit., p. 121)

As autoras me permitem refletir em alguns sentidos no intuito de continuar argumentando sobre a importância do livro escolar como fonte de pesquisa em história da educação. Um desses sentidos diz respeito ao aspecto da formação do leitor que se dá, no meu entendimento, sob exigências específicas da instituição escolar e, por essa razão, há que se considerar a sua contribuição para a formação de um tipo de leitor, o acadêmico fundamentalmente, que se correlaciona à sua natureza e à sua especificidade. O outro vincula-se a um projeto de formação de e para a infância. São os livros escolares que, em grande medida, contribuíram e contribuem por meio de textos elaborados quer em verso, quer em prosa, para o desenvolvimento nas instituições escolares da noção de infância bem educada: "uma nova noção moral" que, segundo Ariès (1981), seria preservadora das rudezas e da imoralidade e que começou a se formar no século XVII. Exemplo disso se acha referido em Bittencourt (1993) quando registra que durante o século XIX, no Brasil, Martin Francisco de Andrada "ao especificar os três níveis de ensino que deveriam compor a escolarização formal brasileira, preocupou-se em declarar as características das obras destinadas a cada um dos graus de ensino (...). Haveria livros de leitura com histórias morais para despertar os bons sentimentos, benevolência, amizade e tolerância". Nesse sentido, veja a seguir uma passagem de um texto dentre aqueles que compõem um livro publicado em língua italiana para ser utilizado em escolas desses imigrantes no Brasil no final do XIX: 


\section{Amor Ao Estudo}

Lodovico Muratori era um pobre rapaz muito inteligente e ávido de saber, que não possuía nenhuma condição financeira para freqüentar a escola.

Ele nascera naqueles tempos em que a instrução era reservada apenas aos ricos e aos abastados. Os rapazes pobres, não podendo pagar o mestre, permaneciam na ignorância.

Mas, em Lodovico, o desejo do saber era muito forte; tanto que, mesmo em pleno inverno, ele andava acocorado próximo à janela da escola.

E lá ficava ele, batendo os dentes de frio e todo ouvidos, para recolher alguma palavra do mestre e aprender alguma coisa.

O mestre que sempre observava aquele menino encostado à janela, pensou que ele viesse por curiosidade, e num belo dia foi para fora, determinado a dar-lhe um puxão de orelha. (...) ${ }^{4}$

O desenrolar da história revelará que a conduta virtuosa de Lodovico, quando insiste, apesar das intempéries, em utilizar-se dos meios de que dispõe para ter acesso ao saber, desperta sentimentos de compaixão e benevolência por parte do professor que acabará por oferecer-Ihe aulas gratuitas.

O texto acima pode também ser entendido como representativo de um momento histórico no qual certos valores eram cultivados e apreciados, assim como de concepções de educação cuja base de sustentação achase no campo da filosofia que privilegia a abordagem valorativa.

Textos de livros didáticos podem conter mensagens que aparecem na forma de poesia, revelando um estilo literário em que conteúdo e forma se sobrepõem, devendo ser assimilados pelo aprendiz. A título de exemplo reporto-me a uma cartilha publicada em língua italiana que circulou no Brasil no mesmo período do livro citado anteriormente:

\section{O Princípio}

Para o seu papai

Para a mamãezinha

Faz prece a Deus

A boa menina. ${ }^{5}$ 
Observe-se que o formato do texto é de poesia e prega, como princípio de referência para a vida da criança, a família representada por pai e mãe por quem o bom aluno deve interceder a Deus. Importa ressaltar que aquela cartilha encerra com esse princípio, trazendo subjacente a idéia do zelo que o infante deve dedicar aos pais. Há, concomitantemente, a presença de uma concepção religiosa de formação da infância.

Os livros didáticos usados em escolas de imigrantes italianos no Brasil trazem, além de uma forte conotação religiosa, também uma patriótica. Nesse sentido é possível dizer que aquele país pretendeu expandir para as fronteiras de além-mar o espírito de nação que se achava em formação numa Itália recentemente unificada, quando da grande imigração para o Brasil, baseado principalmente na geografia e na história daquele país. Desse modo, para Lajolo e Zilberman (1999, p. 121), o livro didático é "poderosa fonte de conhecimento da história de uma nação que, por intermédio de sua trajetória de publicações e leituras, dá a entender que rumos seus governantes escolheram para a educação (...)".

No caso específico do imigrante italiano, a educação se direcionaria no sentido da formação de espírito nacional, cultivando naquele sujeito distante da pátria o amor pela terra longínqua, como foi possível constatar em textos destinados a escolas italianas no Brasil.

De certa forma, no Brasil dos fins do século XIX, não foi diferente. Segundo Bittencourt, apesar de ter permanecido a concepção de que o livro didático era fundamental para o professor,

era essencial garantir a difusão do veículo nação-território, necessitando-se dos estudos de geografia para o conhecimento do espaço físico do "país" e da História Nacional para legitimar as formas de conquista do "continente que é o Brasil". Os livros didáticos deveriam sistematizar e divulgar tais conhecimentos e o Estado incentivou uma produção local capaz de auxiliar a formação do "sentimento nacionalista", sem deixar, entretanto, que as futuras gerações de letrados perdessem o sentimento de pertencer ao mundo civilizado ocidental. (1993, pp. 30-31)

Significa dizer também que o livro didático "é portador de uma memória nacional - (...) formador de identidades, evidenciando saberes já consolidados, 
aceitos socialmente como 'versos autorizados' da história da nação e reconhecidos como representativos de uma origem comum" (Fonseca, op. cit.).

Com efeito, parece-me importante avançar nessa compreensão, principalmente quando não se pode perder de vista a existência da política do livro didático visando à formação das massas populares com base em conhecimentos a que estas deveriam ou não ter acesso, ${ }^{6}$ o que significa não só o controle sobre os conteúdos escolares a serem ensinados e, de certo modo, o controle sobre as práticas escolares, como também sobre a produção desse tipo de livro.

Por outro lado, pouco sabemos sobre as práticas educativas e os seus componentes, que é o que constituiu e constitui a vida cotidiana das escolas. É sobre isso que incide a preocupação a seguir.

\section{O livro escolar como referência de um fragmento da cultura escolar}

Em se tratando de livros que foram organizados e distribuídos em escolas do século XIX e início do XX, podemos observar, em seu conjunto, elementos diferenciados de vários âmbitos da cultura social mais ampla, assim como os diferentes valores que fizeram parte da cultura escolar de certa época e sociedade. É particularmente nesse aspecto que recai minha preocupação com esse tipo de fonte, justamente porque ele nos permite, como já dissemos, olhar a instituição por dentro a partir de sua análise interna. Nesse sentido, entendo que a contribuição avança pelo fato de não se restringir exclusivamente às práticas escolares, mas também, e principalmente, ao seu conteúdo, uma vez que os elementos contidos no livro dão vida e, ao mesmo tempo, significado às práticas escolares.

Por isso, o conceito de Julia sobre cultura escolar parece-me oportuno para pensarmos em alguns aspectos pertinentes à análise desse material. Para esse autor, cultura escolar significa

um conjunto de normas que definem saberes a ensinar e condutas a incorporar e um conjunto de práticas que permitem a transmissão desses saberes e a incorporação desses comportamentos, normas e práticas ordenadas de acordo com finalidades que podem variar segundo as épocas (finalidades religiosas, sociopolíticas ou simplesmente de socialização). Normas e práticas não podem ser 
analisadas sem que se leve em conta o corpo profissional dos agentes que são chamados a obedecer a essas normas e, portanto, a pôr em ação dispositivos pedagógicos encarregados de facilitar sua aplicação, a saber, os professores. (Julia 1993, p. 15)

Com efeito, quando pensamos em normas, situamo-nos na direção metodológica de pensar com base em uma perspectiva que aponta para normalizações sociais válidas numa época e contexto histórico, considerando condutas e comportamentos socialmente válidos e aceitáveis do ponto de vista moral e ético, por exemplo, quanto a leis (legislação educacional). Portanto, são as normalizações sociais que a priori determinam o que deve ou não ser ensinado nas escolas. De certo modo, a legislação legitima as expectativas valorativas que a sociedade quis ou quer ver disseminadas por meio da escola. Contudo, há que se pensar também na perspectiva de Bourdieu (1983) quando considera que

\begin{abstract}
é preciso abandonar todas as teorias que tomam explícita ou implicitamente a prática como uma reação mecânica, diretamente determinada pelas condições antecedentes e inteiramente redutível ao funcionamento mecânico de esquemas preestabelecidos, "modelos", "normas", ou "papéis", que deveríamos, aliás, supor que são em número infinito, como o são as configurações fortuitas dos estímulos capazes de desencadeá-los. (p. 64)
\end{abstract}

Nesta perspectiva, trata-se de evitar analisar a escola do enfoque exclusivo da reprodução mecânica de determinações gerais e hierárquicas, mas pondo em questão as compreensões e os usos que os diferentes sujeitos escolares tiveram e fizeram dessas normas e determinações.

Isso é possível por meio da análise do conjunto das práticas, já que elas representam o lugar supremo em que os saberes e as condutas eram inculcados pela apropriação que os agentes educacionais, principalmente os professores, faziam tanto dessas normas, quanto das próprias práticas que consubstanciaram "saberes e condutas a inculcar", visando a incorporação de certos comportamentos.

Por outro lado, mesmo que consideremos a prática no que diz respeito à sua organização metodológica, esta, no entanto, não é suficiente para 
explicar o conteúdo, ou seja, aquilo que faz com que a prática adquira vida e, portanto, seja suficiente para demonstrar o conteúdo dos saberes a serem transmitidos, levando-se em conta uma dada sociedade e um dado momento histórico. Decorre disso a importância de que sejam feitas análises sob o prisma de certos valores de uma época. Quer na forma de uma simples narrativa ou de poesia de abordagem histórica, política ou geográfica, os textos que compuseram os livros escolares na trajetória histórica da educação escolar são registros a serem decodificados no que se refere aos saberes a inculcar e que tiveram como instrumento de inculcação as práticas educativas escolares.

Igualmente importante é que aquela compreensão de cultura escolar nos permite investigar também a finalidade do livro didático veiculado num certo lugar e momento histórico específicos, admitindo sua variação como própria de uma época, quando contribuiu "para a construção de estilos, de comportamentos (...), de formas de sentir e viver" (apud Nunes 1992), de acordo com o seu tempo.

O livro escolar, ao fazer parte da cultura da escola, não integra essa cultura arbitrariamente. É organizado, veiculado e utilizado com uma intencionalidade, já que é portador de uma dimensão da cultura social mais ampla. Por isso, esse tipo de material serve como instrumento, por excelência, da análise sobre a "mediação" que a escola realiza entre a sociedade e os sujeitos em formação, o que significa interpretar parte de sua função social.

Azanha (1990-1991) contribui para pensar no livro escolar como componente do jogo das relações sociais escolares. Justamente porque a escola tem uma cultura própria e, por essa razão, específica. No universo dessa cultura é possível entender, por exemplo, o significado das práticas, sem perder de vista o uso que tais práticas engendraram no livro didático, buscar investigá-las considerando-o um entre outros dos correlatos dessas práticas. Nesse sentido, esse autor nos convida ainda a pensar que o sucesso e o insucesso do aluno não podem deixar de ser analisados fora dos correlatos das práticas educativas escolares.

Tal compreensão me remete a uma experiência escolar de infância nos idos de 1960 num grupo escolar. Na sala de aula, diariamente realizávamos um ritual que parecia deveras importante para a professora, que iniciava o período de estudos chamando um aluno para que realizasse a leitura de um texto do livro (a lição do dia). O aluno indicado deveria levantarse e, ao lado da carteira, em posição ereta, deveria iniciar a leitura em voz 
alta, pausadamente, tomando o cuidado em segurar o livro com a mão direita e com o polegar sustentando-o ao meio por dentro. Este era um formato ritualístico de procedimento de leitura escolar, uma prática pedagógica muito mais centrada na forma que no conteúdo.

Certamente, o cumprimento ou não desse ritual constituía-se numa referência comportamental para avaliação do desempenho escolar. Além disso, esse tipo de ritual pedagógico era portador de um significado simbólico em torno do livro, da leitura e do conhecimento, pela mensagem que trazia. A postura ereta do aluno ao lado da carteira, por sua vez, demonstra uma dentre as formas de expressões disciplinares praticadas no interior da escola. Ela revela uma conduta que deveria ser adotada não só diante do conhecimento, mas também do cumprimento de certas exigências para tornar-se leitor. Por isso, "o livro didático, ao transmitir o conhecimento, realizava a socialização da leitura, mas tinha igualmente como tarefa desenvolver hábitos individuais no leitor" (Bittencourt, op. cit., p. 288).

Desvendar o livro escolar é também contribuir para fazer a arqueologia das práticas escolares por meio dos materiais que compuseram o trabalho pedagógico desenvolvido na escola ao longo do tempo.

Os conteúdos contidos no livro escolar, neste entendimento, fazem parte da cultura escolar, uma vez que representam um dos aspectos do currículo. Por isso, torna-se importante compreender currículo

como a cultura real que surge de uma série de processos, mais que como um objeto delimitado e estático que se pode planejar e depois implantar; aquilo que é, na realidade, a cultura nas salas de aula, fica configurado em uma série de processos; as decisões prévias acerca do que se vai fazer no ensino, as tarefas acadêmicas reais que são desenvolvidas, a forma como a vida interna das salas de aula e os conteúdos de ensino se vinculam com o mundo exterior, as relações grupais, o uso e o aproveitamento de materiais, as práticas de avaliação, etc. (Gimeno Sacristán 1995, pp. 86-87)

As práticas pedagógicas escolares, quer ocorram na relação imediata com o aluno, quer nas relações mais abrangentes no interior da instituição escolar, englobam essa concepção curricular, já que é por esse meio que a escola desempenha sua função transitiva representada pela intermediação que realiza entre o sujeito e o mundo (Azanha, op. cit.). 
O currículo tem uma função social que é a de imprimir efeitos positivos ou negativos como componente supremo dessa intermediação realizada pela escola. Contudo, o currículo escolar não é uma construção natural. Por isso,

\begin{abstract}
a desconstrução de uma imagem "natural" do currículo é uma condição prévia à compreensão do modo como as práticas e as disciplinas escolares construíram um conjunto de categorias através das quais nos situamos em relação ao mundo. A forma como, no passado e no presente, o conhecimento foi separado do método, a cognição do afeto ou o intelecto do corpo é parte de uma alquimia complexa que transforma as disciplinas (integradas nos seus espaços próprios) em currículo. (Musgrave 1988, apud Nóvoa, p. 16)
\end{abstract}

Talvez o indicativo mais importante dos limites, concepções e abordagem das disciplinas escolares, como parte dos nexos de um conjunto curricular, esteja registrado nos livros escolares.

A cultura escolar ao longo do tempo não tem estado exclusivamente repleta de normalizações, de saberes, enfim, de práticas, mas antes de tudo de mentalidades que definiram os seus componentes em épocas históricas específicas. Mentalidades prevalentes que podem emergir com a possibilidade de realização de uma arqueologia também de mentalidades que compuseram a cultura escolar de uma época.

\title{
Considerações em torno da produção
}

Outro elemento importante, ao se tomar o livro escolar como fonte de pesquisa em história da educação, é considerá-lo ainda do ponto de vista da produção, principalmente com o passar do tempo, na medida em que vão se tornando mais complexas as relações entre mercado e escola. Isso se deve ao fato de que produzir livros também passa a significar possibilidades de venda e não só de veiculação de valores e formação de condutas socialmente válidas.

À medida que vamos avançando no tempo, o livro escolar passa a ser sinônimo de mais valia. É por esta razão que, para Lajolo e Zilberman (1999), embora ele seja o primo pobre da literatura, é, ao contrário, o primo rico das 
editoras, na medida em que se torna bem de consumo, "um produto típico da indústria cultural, um bem destinado ao consumo que editores e autores têm interesse em comercializar, uma mercadoria entre outras que circula pelo mercado e produz lucro, muito lucro" (apud Bittencourt, op. cit., p. 77).

Com efeito, as vantagens comerciais do livro didático fizeram com que este viesse a se tornar o texto impresso de maior circulação, particularmente no Brasil, a partir da segunda metade do século XIX (idem).

$\mathrm{Na}$ compreensão de cultura escolar aqui adotada, a relação entre livro didático, comercialização e lucro, exige uma maior abrangência. Justamente porque, somadas às normas educativas e sociais, acham-se as de mercado. Elas incidem sobre critérios comerciais. Assim, a organização do livro escolar, no que se refere à forma como uma parcela do conhecimento foi distribuída no interior da escola, não se deu exclusivamente por critérios pedagógicos (o que, aliás, parece ter influenciado pouco), mas sobretudo por critérios que antes de mais nada pudessem torná-lo vendável. Para isso concorrem os títulos, as ilustrações e o papel.

Podemos dizer que a comercialização do livro didático esteve cercada de desafios constantes pelo fato de que foi e tem sido preciso aliar preço à qualidade de impressão e de encadernação, a fim de que pudesse continuar sendo acessível a um grande contingente populacional escolar.

O parâmetro da comercialização, por outro lado, requer que sejam postos em questão, como elementos de análise, os pressupostos pedagógicos que supostamente orientam a organização e a produção desse tipo de material escolar. Além da natureza diferenciada que está na base da existência desse tipo de livro, ele exige uma organização interna diferenciada em virtude das exigências didáticas que lhe são atribuídas, tanto no que se refere à distribuição do conhecimento, quanto pelo modo de enveredar por ele através das tarefas correspondentes às informações a serem assimiladas.

Provavelmente, nenhum material escolar sofreu tanto as influências das leis de mercado quanto esse. Fundamentalmente porque as políticas do livro escolar mantiveram conectados os interesses estatais aos privados.

Atentar para essas relações é admitir que o formato desse elemento da cultura escolar não é natural e, por essa razão, desprovido de intencionalidades mercantilistas. Por esta via certamente não estarei incorrendo em erro ao afirmar que o livro escolar talvez seja a expressão menos visível, 
porque sutil, de que ter acesso a uma parcela de conhecimento, o escolar, também significou e tem significado distinguir-se social e economicamente. Principalmente quando é garantido pelo Estado a um segmento populacional economicamente menos favorecido.

\title{
Notas
}

1. Por livro escolar estamos entendendo um compêndio especificamente organizado para fins de educação escolar e que pode ou não abranger diferentes áreas de conhecimento, com propósito formativo, segundo valores que se deseja sejam veiculados.

2. Referimo-nos destacadamente a livros didáticos utilizados em escolas no Brasil durante o século XIX e início do século XX, em suas primeiras décadas.

3. Para essas autoras o livro didático é uma das mais antigas modalidades de expressão da escrita e tem sua gênese nos escritos da poética do Aristóteles e no Institutio Oratoria de Quintiliano, nos séculos IV. a.C. e I d.C. respectivamente. Cf. Lajolo e Zilberman 1999, p. 120.

4. Bocci, S. et ali. Lo Scolaretto Italo-Brasiliano, Libro III ad uso della classe terza elementare. Compilato per uso delle scuole Italiane al Brasile conforme ultimi programmi governativi italiani e brasiliani, p. 4. Ressalte-se que, embora esse livro escolar não contenha ano de publicação, exemplos de correspondências existentes indicam que sua veiculação e sua utilização em escolas italianas no Brasil, no estado de São Paulo, deu-se entre 1895 e 1900.

5. Silabário Italiano Ilustrato, per la sezione inferiore della prima classe elementare maschile e femminile ad uso delle scuole italiane al Brasile, p. 39. Informações contidas em texto do Silabário permitem que situemos o período de publicação em torno de 1896.

6. Ver nesse sentido Bittencourt, obra citada.

7. Nunes utiliza o termo "instituição mediadora" na obra citada. Veja nesse sentido especialmente o capítulo II da obra referida de Bittencourt sobre o livro didático.

\section{The didactic book as a source of research on Education History}

\begin{abstract}
This article is about the didactic book as a source to research on Education History. It is considered possessing the desired values to be transmitted in such a historical period and at the same time it has a project of nation which is constructed by means of the school education. This article also understands that this kind of material is part of the universe of the school culture and that is the importance of using it to comprehend the school pratice in the educational instituions through the Education History. This article considers the production and commercialisation of the didactic book as elements to be examined in its organisation.
\end{abstract}




\section{Bibliografia}

ARIÈS, P. História social da criança e da família. Rio de Janeiro: Zahar, 1981.

AZANHA, J.M.P. "A cultura escolar brasileira: Um programa de pesquisas". Revista de Educação. Universidade de São Paulo, dez., jan., fev. 1990-1991.

BITTENCOURT, C.M.F. Livro didático e conhecimento histórico: Uma história do saber escolar. Tese de doutoramento, FFLCH, Universidade de São Paulo, 1993.

BOURDIEU, P. Sociologia. São Paulo: Ática, 1983.

CARVALHO, M.M.C. de e NUNES, C. "Historiografia da educação e fontes". Trabalho apresentado na $15^{\text {a }}$ Reunião Anual da Anped, Caxambu (MG), 1992.

CHARTIER, R. A história cultural: Entre práticas e representações. Lisboa: Difel, 1990.

FONSECA, T. de L. e. "O livro didático de História: Lugar de memória e formador de identidades". In: Simpósio Nacional da Associação Nacional de História, 20, Florianópolis, 1999. História: fronteiras / Associação nacional de História. São Paulo: Humanitas, FFLCH, ANPUH, 1999.

GIMENO SACRISTÁN, J. "Currículo e diversidade cultural". In: Territórios contestados: O currículo e os novos mapas políticos e culturais. Tomaz Tadeu da Silva e Antônio Flávio Barbosa Moreira (orgs.). Petrópolis, RJ: Vozes, 1995.

JULIA, D. "La culture scolaire comme objet historique". Conferência de Encerrramento do ISCHE, 15, 1993.

LAJOLO, M. e ZILBERMAN, R. A formação da leitura no Brasil. São Paulo: Ática, 1999.

NÓVOA, A. História da educação: Perspectivas atuais. Mimeo, s./d.

NUNES, C. "Historiografia da educação brasileira: Novas abordagens de velhos objetos". Teoria e Educação, 6, 1992. 